\title{
Aseptic Pseudoarthrosis of Olecranon: Epidemiological Features and Therapeutic Assessment
}

\author{
Raphael Dallo Gogoua*, Moctar Traoré, Bi Yao, Armand Yépié, Maurice Kouamé, Michel Anoumou \\ Department of Orthopaedic Surgery and Traumatology, C.H.U. Treichville, Abidjan, Cote d'Ivoire \\ Email: ^gogouad@yahoo.fr, *gogouadallo60@gmail.com
}

How to cite this paper: Gogoua, R.D., Traoré, M., Yao, B., Yépié, A., Kouamé, M. and Anoumou, M. (2017) Aseptic Pseudoarthrosis of Olecranon: Epidemiological Features and Therapeutic Assessment. Open Journal of Orthopedics, 7, 117-125. https://doi.org/10.4236/ojo.2017.74014

Received: February 13, 2017

Accepted: April 27, 2017

Published: April 30, 2017

Copyright (c) 2017 by authors and Scientific Research Publishing Inc. This work is licensed under the Creative Commons Attribution International License (CC BY 4.0). http://creativecommons.org/licenses/by/4.0/

\begin{abstract}
Introduction: Pseudoarthrosis is one of the most dreadful complications of olecranon fractures. It seriously compromises the function of the elbow. jectives: To determine the epidemiological factors of this complication in order to prevent them and to assess the results of the therapeutic management. Material and method: This was a retrospective study that involved patients with olecranon pseudoarthrosis who were treated in the department between January 2006 and December 2016. The diagnosis of pseudoarthrosis was made at least 6 months after the management of the fracture. There were 16 men and 5 women. We analyzed the epidemiological factors, the treatment of pseudoarthrosis, and the postoperative outcome. Results: The incriminated factors were the complexity of the fracture line and the quality of treatment of the recent fracture. The osteosynthesis of pseudoarthrosis is similar to that of recent fractures. It requires in some cases a bone graft. The results of the treatment are satisfactory with $100 \%$ of consolidation, and a good functional result in $75 \%$ of the cases. Conclusion: The treatment of olecranon pseudoarthrosis is based above all on prevention by an optimal management of the recent fractures. The curative treatment gives satisfactory functional results.
\end{abstract}

\section{Keywords}

Fracture, Pseudoarthrosis, Olecranon, Elbow

\section{Introduction}

Olecranon fractures are common due to its superficial anatomical location [1]. Surgical treatment should enable early mobilization of the elbow joint. The most common complications of fractures of the olecranon are decreased from range of elbow motion, ulnar neuropathy, post-traumatic arthritis, instability, and 
nonunion [2]. The last is relatively rare but has been reported to occur in $5 \%$ of all olecranon fractures [3]. It is challenging to treat because pain is usual and there is often some instability and limitation of motion leading to considerable functional disability [4] [5] [6]. The aim of this work is to describe the epidemiological factors, and to assess our therapeutic results of the management of the olecranon pseudarthrosIs.

\section{Material and Methods}

This was a continuous retrospective study on the basis of 21 records at the Department of Orthopedics and Traumatology at Treichville University Hospital from January 2006 to December 2016. We included all patients who had aseptic pseudoarthrosis of olecranon treated in the department and with a postoperative follow-up of 6 months or more. Three cases of septic pseudoarthrosis of the olecranon were excluded. The treatment of pseudoarthrosis consisted of a posterior approach to the site, a resection of intra-articular fibrosis, the assessment of the degree of osteoporosis, the articular mobilization. A cortical spongy graft was sometimes necessary. The restraint was ensured by a synthetic material.

The epidemiological analysis of our results was based on the type of fracture according to the Mayo Clinic classification (Figure 1) [7], the existence of asso-
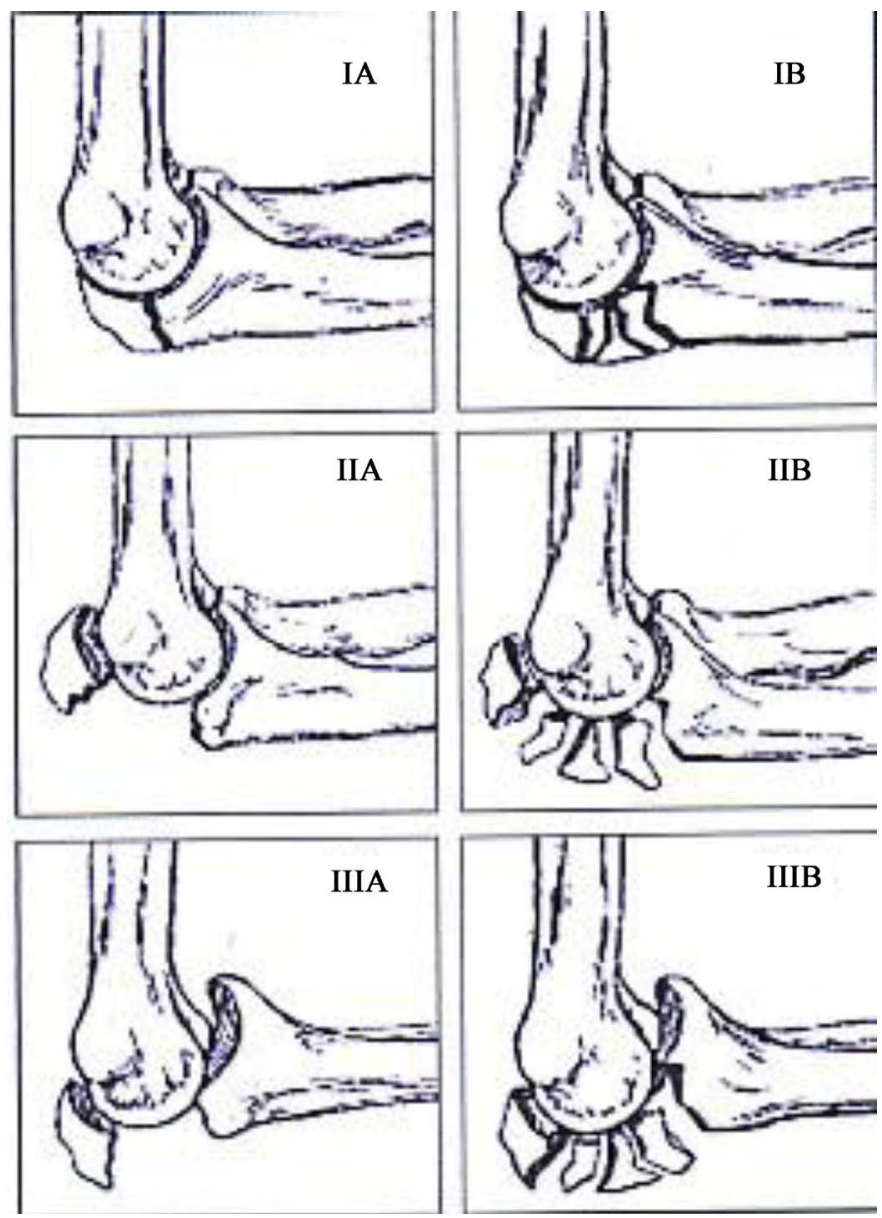

Figure 1. Mayo Elbow Classification [7]. 
Table 1. Mayo clinic scores for clinical evaluation of the elbow [8].

\begin{tabular}{|c|c|c|}
\hline \multirow{4}{*}{ Pain Intensity (45 points) } & None & 45 pts \\
\hline & Mild & $30 \mathrm{pts}$ \\
\hline & Moderate & 15 pts \\
\hline & Severe & 0 point \\
\hline \multirow{3}{*}{ Motion (20 points): Arc of motion } & Arc of motion greater than $100^{\circ}$ & 20 pts \\
\hline & Arc between $50^{\circ}$ to $100^{\circ}$ & 15 pts \\
\hline & Arc less than $50^{\circ}$ & 5 points \\
\hline \multirow{3}{*}{ Stability (10 points) } & Stable & 10 pts \\
\hline & Moderate stability & $5 \mathrm{pts}$ \\
\hline & Grossly unstable & 0 points \\
\hline \multirow{5}{*}{ Function (tick as many as able) (25 pts) } & Can comb hair & 5 pts \\
\hline & Can eat & $5 \mathrm{pts}$ \\
\hline & Can perform hygiene & $5 \mathrm{pts}$ \\
\hline & Can don shirt & $5 \mathrm{pts}$ \\
\hline & Can don shoe & 5 points \\
\hline \multirow{4}{*}{ Total Score } & Excellent & $90-100$ pts \\
\hline & Good & $75-89$ pts \\
\hline & Fair & $60-74$ pts \\
\hline & Poor & $0-59 \mathrm{pts}$ \\
\hline
\end{tabular}

ciated lesions, the type of treatment of the recent fracture and its postoperative follow-up.

The analysis of the treatment of pseudoarthrosis concerned the nature of the osteosynthesis, the different operative times with or without a cortical spongy graft and the postoperative outcome. The evaluation of our results was assessed according to the Mayo Clinic Elbow criteria (Table 1) [8].

\section{Results}

\subsection{Epidemiological Data}

- Patients: There were 16 men and 5 women with an average age of 32 years with extremes of 17 years and 58 years. The dominant limb was concerned in 18 cases; it was the right limb. Road accidents were responsible in 15 cases followed by sports accidents ( 3 cases), domestic accidents ( 2 cases) and 1 assault by firearm.

- Types of initial lesions: Out of the 21 patients, 3 had a treatment called "traditional" performed by traditional therapists. For these patients we did not have an initial X-ray. The Mayo clinic classification gave 2 (9.52\%) fractures of type I (Figure 2), 12 (57.14\%) fractures of Type II and 4 (19.04\%) fractures of Type III (Figure 3, Figure 4). These lesions were initially opened in 7 (33.3\%) patients.

- Associated lesions: this pseudoarthrosis was associated with a homolateral fracture of the forearm in 3 cases, dislocation of the elbow with fracture of the humerus ( 1 case) and fracture of the femur (1 case). 


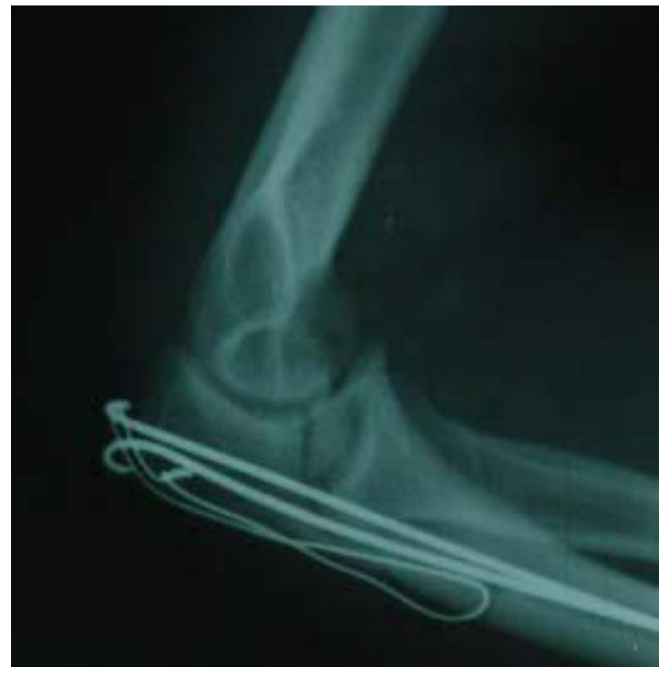

Figure 2. Pseudarthrosis of fracture type I treated by bracing.

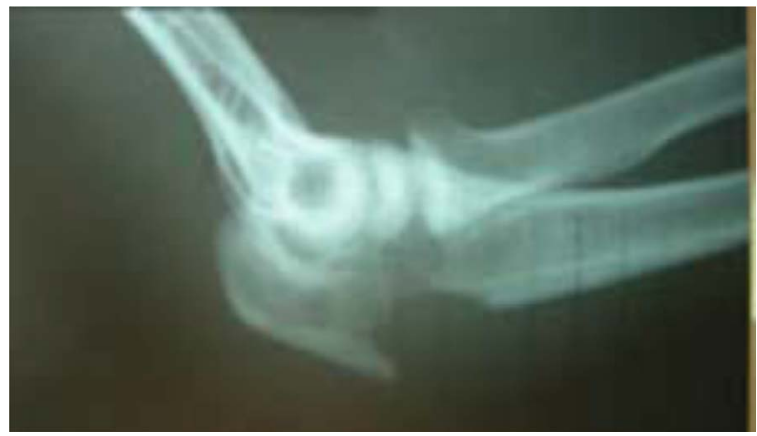

Figure 3. Olecranon pseudarthrosis secondary to single fracture AI treated orthopedically.

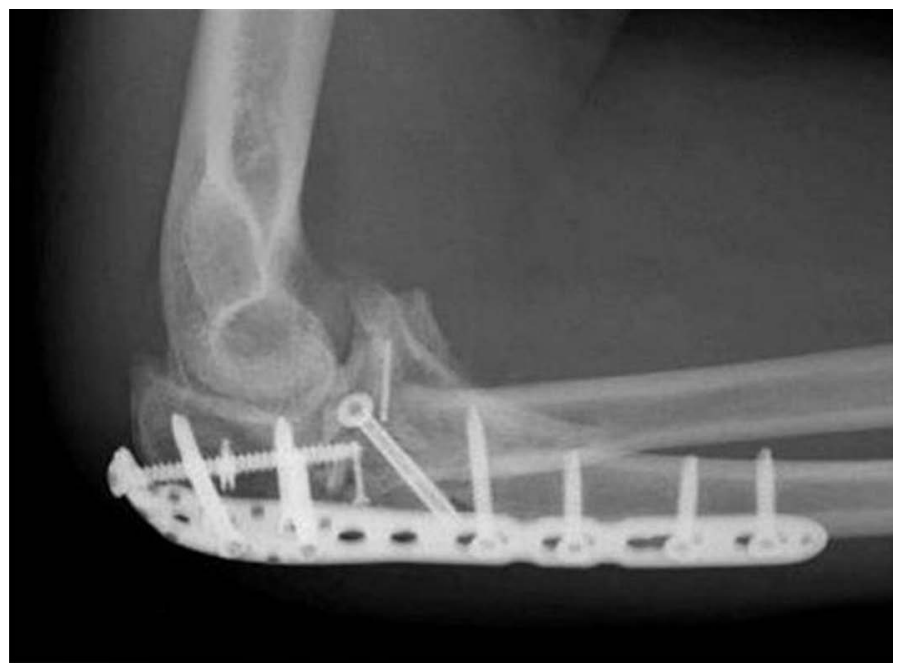

Figure 4. Osteosynthesis by hooked screw plate of a pseudarthrosis of complex fracture (fracture type III).

\section{- Initial treatment}

The treatment called "traditional" was performed in 3 patients. This unconventional treatment consisted of an improvised immobilization that did not respect any principle of immobilization. 
- A brachio ante brachiopalmar plaster immobilization was performed in 2 patients who had an undisplaced type I fracture. The removal of the plaster on day 35 for the beginning of the rehabilitation led to diastasis and then to pseudoarthrosis of the site of the fracture.

- Bracing had been performed in 15 cases. 10 fractures were type II of the Mayo Clinic classification and had been treated by the bracing technique. 3 of these osteosyntheses let persist an inter-segment deviation. 5 fractures were type III and had also been treated by the bracing technique.

- 1 centromedullary screwing was performed on a type I fracture.

The postoperative period was marked by 5 cases of pin migration, 2 cases of superficial sepsis which had dried up after local care.

Rehabilitation after intervention began on average at 3 weeks. Migrations were observed in 3 complex fractures type III whose rehabilitation had started earlier (before 3 weeks).

\subsection{Clinical Data}

Pseudoarthrosis had been developing for 6 months minimum and 15 months maximum with an average of 7 months. Patients in our series had consulted for elbow pain in 15 cases (66.6\%), relative functional impotence all 21 patients (100\%) and elbow deformity in 10 cases (47.6\%). The elbow was limited in all cases; there was no case of ankylosis of the elbow. Passive and active mobility averaged $0 / 10 / 90^{\circ}$; pronation and supination were complete and painless in 18 patients; limited in 3 patients.

\subsection{Therapeutic Data}

After the approach of the site of pseudoarthrosis, resection of intra-articular fibrosis and avivement of bone surfaces, a cortical spongy graft was intercalated in 7 patients who had multi-fragmental lesions or a fairly significant osteoporosis. This graft intercalated in the inter-fragmentary space, spread out the articular cartilage of the olecranon without surpassing it. Stabilization was ensured by bracing in 16 cases, by a hooked plate in 5 cases.

Table 2 shows the epidemiological, clinical and therapeutic characteristics of patients.

Table 2. Clinical epidemiological and therapeutic characteristics of patients.

\begin{tabular}{|c|c|c|c|c|c|c|c|}
\hline $\begin{array}{c}\text { Average } \\
\text { age (year) }\end{array}$ & Sex & Causes & Side & Mayo classif of the initial frac & Type of frac & Initial treatment & $\begin{array}{l}\text { Surgical treatment } \\
\text { of pseudarthrosis }\end{array}$ \\
\hline \multirow[t]{4}{*}{32} & $M=16$ & Road accident $=15$ & Left $=03$ & Type I = 02 & Open $=07$ & Orthopaedic $=02$ & bracing $=16$ \\
\hline & $\mathrm{F}=05$ & Sport-accident $=03$ & Right 18 & Type II = 12 & Closed $=14$ & Surgery $=16$ & Screw Plate $=05$ \\
\hline & & domestic accid $=02$ & & Type III = 04 & & No treatment $=03$ & \\
\hline & & Ballistic accident $=01$ & & Inconnu $=03$ & & & \\
\hline Total & 21 & 21 & 21 & 21 & 21 & 21 & 21 \\
\hline
\end{tabular}




\subsection{Postoperative Outcome}

Treatment progress was assessed with an average follow-up of 6 months. All 21 patients were taken into account. We have observed:

- A hematoma in 2 patients. They were linked to an inadequate drainage. Local care with daily dressings allowed healing within 21 days.

- 1 case of migration - expulsion of the pins at the beginning of rehabilitation. This was postponed. The follow-up was uneventful.

We did not observe nervous and vascular complications.

- Amyotrophy of the arm was observed in all patients. It had no functional impact.

- A limitation of the elbow in all patients (assessed) but improved in all cases compared to the preoperative state.

- Consolidation was achieved in all patients. The average time was 3.5 months with extremes of 3 months and 6 months.

The outcome was found satisfactory in $75 \%$ of the cases according to the criteria retained (Table 2 and Figure 5).

Table 3 shows the functional result according to the criteria of the clinical mayo.

\section{Discussion}

Pseudarthroses are severe late complications of olecranon fractures. Epidemio-

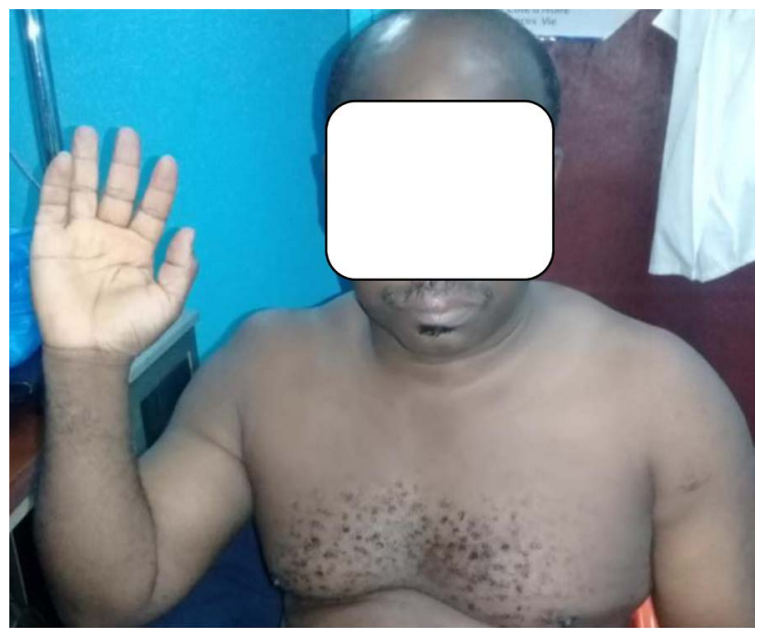

Figure 5. Postoperative evolution after synthesis of a pseudarthrosis of the olecranon.

Table 3. Clinical results according to Mayo clinic score.

\begin{tabular}{cccc}
\hline Score & Points & Number & $\%$ \\
\hline Excellent & $90-100$ & 15 & 71.42 \\
Good & $75-89$ & 04 & 19.05 \\
Fair & $60-74$ & 02 & 9.53 \\
Poor & $0-59$ & 00 & 00 \\
Total & 100 & 21 & 100 \\
\hline
\end{tabular}


logically, they occur at any age with a predilection in young adults. Males are the most exposed [5] [9]. This male predominance may be due to the high frequency of trauma due to road accidents and violent trauma in the male gender. The right side which is predominant in our series is the most involved; no explanation has been found in our series or in the studies of the literature on this predominance. These lesions involve all anatomical types of the Mayo Clinic classification. In our series type II fractures were the most common. Type III fractures accounted for $23 \%$ of all pseudoarthroses. To really assess this impact in our series, it would have been necessary to know the proportion of the different types of recent fractures received; which is not the case. However, multi-fragmentary or type III fractures are the most commonly reported by different authors [10] [11] [12]. In the series of Sané et al. [6], out of 63 olecranon fractures, 12 were multi-fragmentary and 3 (25\%) had evolved towards pseudoarthrosis. The quality of treatment also plays an important role in the occurrence of pseudoarthroses. The absence of suitable treatment in our series led logically to diastasis, synonymous later of pseudoarthrosis. All patients treated by the method called "traditional" or by orthopedic immobilization resulted in pseudoarthrosis. The same was true in the series of Sané and al. [6], where pseudoarthroses of his series were recruited from poorly treated patients; as in the short series of Tiemdjo, T. et al. [10], where all patients had been treated by traditional therapists. Osteosynthesis of poor indication can also lead to pseudoarthrosis. Bracing which is supposed to allow the transformation of tensile forces into compressive force according to the principles of the AO [13], led in our series to pseudoarthrosis in 12 patients, in some cases after a stable osteosynthesis. For Papagelopoulos and Morrey [5], in addition to these factors recognized by all authors, we must add infection which is a source of pin migration, bone loss, osteoporosis, soft tissue stiffness and neurovascular lesions. In our series the precocity of rehabilitation, in principle salutary for the acquisition of the articular function can destabilize the osteosynthesis of a complex fracture. The indication and the surgical technique are therefore essential conditions for the success of osteosyntheses of olecranon fractures. Thus, bracing which is the most used method in the treatment of these lesions should not be used in multi-fragmental fractures, fractures with oblique line, metaphyso-diaphyseal fractures. For a successful bracing, authors have proposed that pins, rather than being parallel and centromedullary, should be oblique and should get stuck in the anterior ulnar cortex. But this technique has sometimes been at the origin of serious neurovascular complications [14]; moreover it has not always prevented the migration of pins [14]. For the choice between centromedullary pins and oblique pins getting stuck in the anterior cortex, it is necessary to carry out multi-centric studies on large samples.

The quality of treatment of recent fractures is therefore the basis of the prevention of olecranon pseudoarthrosis whose treatment is osteosynthesis. This osteosynthesis must be stable from the start and this stability must allow an early and prolonged rehabilitation on an elbow already limited. The different techniques used for the treatment of pseudoarthroses are the same as those of recent 
fractures; by adding, depending on the case, a cortical spongy graft. In our series we used 16 times the bracing technique and 5 times the screwed plate in 7 cases with autologous bone graft. This bracing technique was used by Tiemdjo et al. [10] to treat his 2 pseudoarthroses but without bone graft. Apart from these techniques, other therapeutic modalities exist. They range from the excision of the proximal fragment with reinsertion of the triceps tendon, to intramedullary screwing, and sometimes even to arthroplasty. For Papagelopoulos and Morrey [5], bracing must be the basic technique, associated or not with a cortical spongy graft in simple fractures. The curved screwed plate must be the choice in complex multi-fragmentary fractures. It allows to embed a bone graft and to perform rehabilitation quite early. The other methods must be reserved for complex cases with loss of bone substance, on fragile and multi-operated organisms.

The results of treatment of pseudoarthroses by the technique of bracing and screwed plate with or without bone graft were satisfactory in our series. Consolidation was achieved in all patients and the functional outcome satisfactory. These different results are also found in the different series of the literature [5] [6] [14].

\section{Conclusion}

Pseudoarthrosis is the most common and most feared complication of olecranon fractures. The complexity of the site and the imperfection of the initial treatment are the main causes. The management by the bracing technique or the screwed plate technique associated or not with a bone graft gives satisfactory results. Prevention remains the best treatment by a rigorous indication of the treatment of these fractures.

\section{Limits of the Study}

This study is limited by its retrospective nature, the small sample size and the impossibility of achieving other.

A case-control study on a larger sample will be necessary for future study.

\section{Conflict of Interests}

The authors declare no conflict of interest.

\section{Author's Contributions}

This study was approved by the local ethics committee and all the authors contributed to the writing of this article.

\section{References}

[1] Morrey, B. (1995) Current Concepts in the Treatment of Fractures of the Radial Head, the Olecranon and the Coronoid. Journal of Bone and Joint Surgery, 77, 316-327. https://doi.org/10.2106/00004623-199502000-00019

[2] Cabanela, M.E. (1985) Fractures of the Proximal Ulna and Olecranon. In: Morrey, B.F., Ed., The Elbow and Its Disorders, W.B. Saunders, Philadelphia, 382-399. 
[3] Mayer, P.J. and Evarts, C.M. (1976) Nonunion, Delayed Union, Malunion and Avascular Necrosis. In: Epps, C.H., Ed., Complications in Orthopaedic Surgery, J.B. Lippincott, Philadelphia, 159-175.

[4] Gartsman, G.M., Sculco, T.P. and Otis, J.C. (1981) Operative Treatment of Olecranon Fractures: Excision or Open Reduction with Internal Fixation. The Bone \& Joint Journal, 63, 718-721.

[5] Papagelopoulos, P.J. and Morrey, B.F. (1994). Treatment of Nonunion of Olecranon Fractures. The Bone \& Joint Journal, 76, 627-635.

[6] Sané, A., Diémé, C., Coulibaly, N.F., Bousso, A. and Ndiaye, A. (2008) Evaluation of Surgical Treatment by Bracing Fracture of the Olecranon. Le Mali Medical, 23, 47-49.

[7] Broberg, M.A. and Morrey, B.F. (1986) Result of Delayed Excision of the Radial Head after Fracture. The Bone \& Joint Journal, 68, 669-674. https://doi.org/10.2106/00004623-198668050-00005

[8] Askew, L.I., An, K.N., Morrey, B.F. and Chao, E.Y. (1981) Functional Evaluation of the Elbow. Normal Motion Requirements and Strength Determinants. Orthopaedic Transactions, 5, 304-305.

[9] Anderson, M.L., Larson, N.L., Merten, S.M. and Steinmann, S.P. (2007) Congruent Elbow Plate Fixation of Olecranon Fractures. Journal of Orthopaedics, 21, 386-393. https://doi.org/10.1097/bot.0b013e3180ce831e

[10] Tiemdjo, T.H., Coulibaly, N.F., Kinkpe, C., Dieng, P.W., N'diaye, A. and Seye, S.I.L. (2015) Nonunion of the Olecranon: Report of Two Cases. Revue de la Tunisie Orthopédie Traumatologie, 7, 74-77.

[11] Coonrad, R.W. (1985) Nonunion of the Olecranon and Proximal Ulna. In: Morrey, B.F., Ed., The Elbow and Its Disorders, W. B. Saunders, Philadelphia, 400-413.

[12] Wilkerson, R.D. and Johnson, J.C. (1990) Nonunion of an Olecranon Stress Fracture in an Adolescent Gymnast: A Case Report. The American Journal of Sports Medicine, 18, 432-434. https://doi.org/10.1177/036354659001800418

[13] Müller, M.E., Allgöwer, M., Schneider, R. and Willenegger, H. (1980) Manual of Osteosynthesis-Technique AO. 2nd Edition, Springer-Verlag, Berlin, Heidelberg, New York, 42-46.

[14] Ishigaki, N., Uchiyama, S., Nakagawa, H., Kamimura, M. and Miyasaka, T. (2004) Ulnar Nerve Palsy at the Elbow after Surgical Treatment for Fractures of the Olecranon. Journal of Shoulder and Elbow Surgery, 13, 60-65. 
Submit or recommend next manuscript to SCIRP and we will provide best service for you:

Accepting pre-submission inquiries through Email, Facebook, LinkedIn, Twitter, etc. A wide selection of journals (inclusive of 9 subjects, more than 200 journals) Providing 24-hour high-quality service

User-friendly online submission system

Fair and swift peer-review system

Efficient typesetting and proofreading procedure

Display of the result of downloads and visits, as well as the number of cited articles Maximum dissemination of your research work

Submit your manuscript at: http://papersubmission.scirp.org/

Or contact ojo@scirp.org 